\title{
Balloon Eustachian Tuboplasty treatment of longstanding Eustachian tube dysfunction
}

\author{
Ms. Virangna Taneja; Mr. T. Singh; Mr. Darius Rejali ;Mr. Kevin Kulendra; Dr. Mathew Farr; Dr. Jennifer Robinson
}

\section{Introduction}

Eustachian tube dysfunction is poorly defined condition. It can be defined according symptoms, signs, abnormalities on objective testing or pathological processes.

BET is a recently proposed treatment for ETD. We treated patient with chronic ETD with BET. Objective (otoscopy, pneumo-otoscopy, tympanometry, valsalva and audiometry) and subjective outcome (patient symptoms and ETDQ-7 questionnaire1) were measured.

\section{Method}

Symptomatic adult patient with recurrent glue ear after previous grommets were recruited. Subject's symptoms, signs were noted. Further assessment with audiometry, tympanometry and EDQT-7 questionnaire obtained.

\section{BET Method}

Bielefeld balloon catheter ${ }^{\circledR}$ (Spiggle and Theis) was inserted transnasally into the naso-pharyngeal ostium of the Eustachian tube. The balloon was inflated with saline to 10 atmospheres (1013 kpascal) for 120 seconds. Post procedure follow up was carried out at 3-9months.

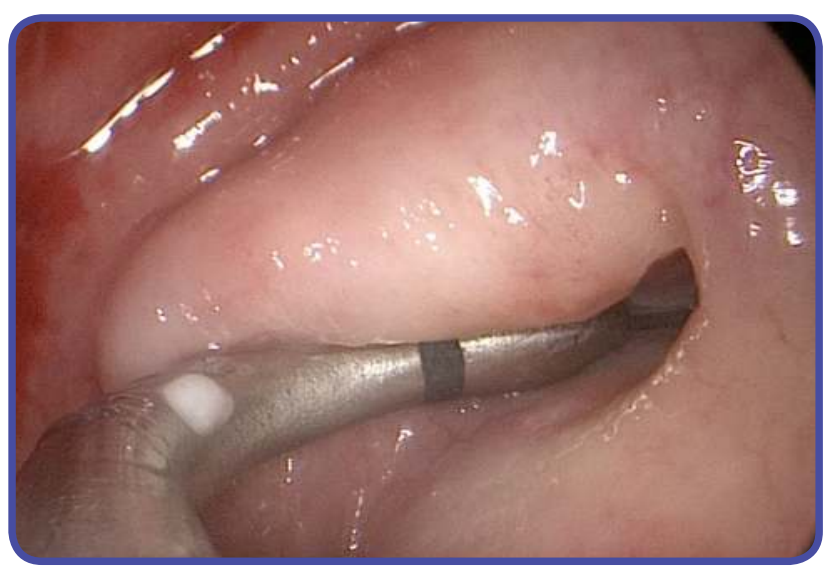

Figure 1. Eustachian Balloon Catheter inserted into left Eustachian Tube.

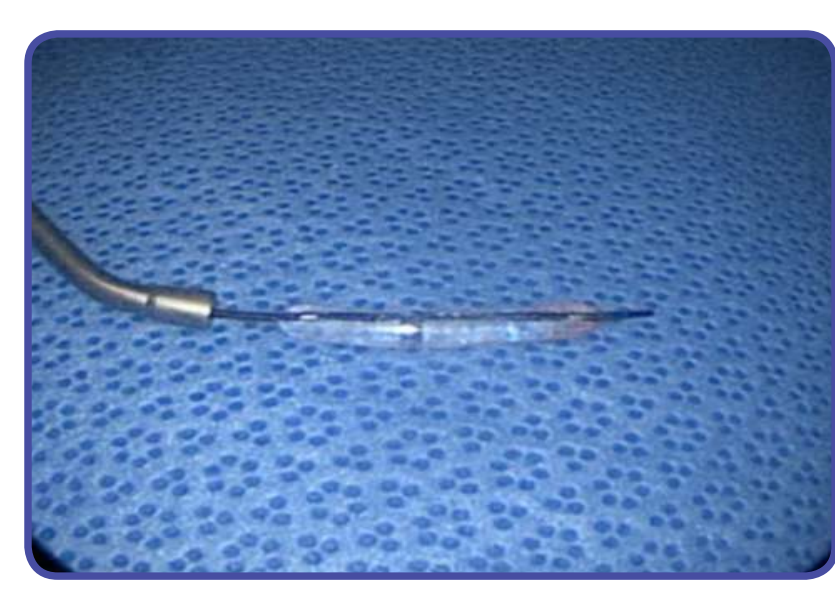

Figure 2. Eustachian Balloon Catheter
Table 1.

\begin{tabular}{|c|c|c|c|c|c|c|}
\hline Ears & $\begin{array}{c}\text { Preoperative } \\
\text { compliance (ck3 }\end{array}$ & $\begin{array}{l}\text { Prepoerative } \\
\text { curve }\end{array}$ & Postoperative & $\begin{array}{c}\text { Compliance } \\
(\mathrm{cm} 3)\end{array}$ & 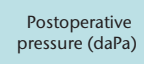 & $\begin{array}{c}\begin{array}{c}\text { Postoperative } \\
\text { curve }\end{array} \\
\text { cots }\end{array}$ \\
\hline 1 & 0 & NP & Flat curve & 0 & $N P$ & Flat curve \\
\hline 2 & 0.2 & $\mid-160$ & Flat curve & 0 & $N P$ & Flat curve \\
\hline 3 & 0.2 & -200 & Flat curve & 0.5 & -240 & Flat curve \\
\hline 4 & 0 & NP & Flat curve & 0.2 & -290 & Flat curve \\
\hline 5 & 0 & $\mathrm{NP}$ & Flat curve & 0.1 & -155 & Flat curve \\
\hline 6 & 0 & NP & Flat curve & 0 & $N P$ & Flat curve \\
\hline 7 & 0 & NP & Flat curve & 0.9 & -325 & Flat curve \\
\hline 8 & 0 & NP & Flat curve & 0 & NP & Flat curve \\
\hline 9 & 0 & NP & Flat curve & 0 & NP & Flat curve \\
\hline 10 & 0 & NP & Flat curve & 0.9 & -325 & Flat curve \\
\hline 11 & 0 & NP & Flat curve & 0 & NP & Flat curve \\
\hline 12 & 0 & NP & Flat curve & 0 & NP & Flat curve \\
\hline 13 & 0 & NP & Flat curve & 0 & NP & Flat curve \\
\hline $\begin{array}{l}\text { Mean } \\
\text { (standard } \\
\text { deviation) }\end{array}$ & $\begin{array}{l}0.09 \\
(0.28)\end{array}$ & & & $\mid \begin{array}{l}0.18 \\
(0.29)\end{array}$ & & \\
\hline $\begin{array}{l}\text { t-test } p \\
\text { value }\end{array}$ & & 0.42 & & & & \\
\hline
\end{tabular}

Table 1.

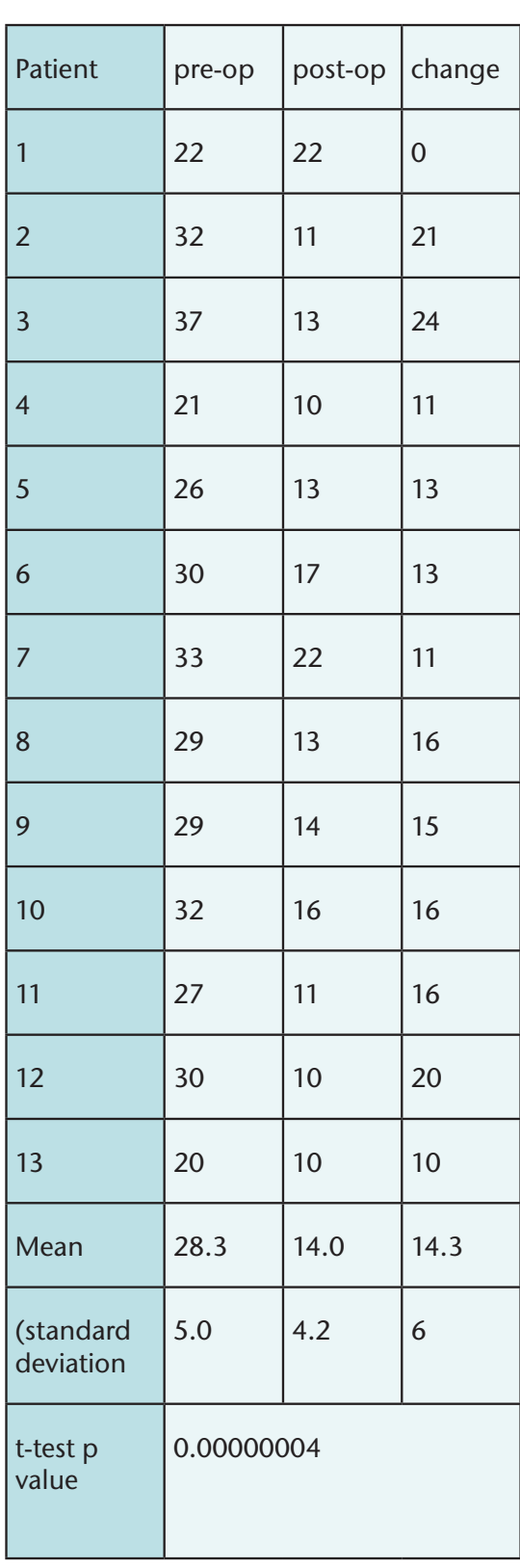

\section{Results}

11 patients ( 9 male and 2 female) with 13 ears ( 2 had bilateral) with mean age of $42.5 y e a r s$ were recruited.

$18.1 \%(2 / 11)$ of the procedures were on the left, $63.6 \%(7 / 11)$ on the right and $18.1 \%(2 / 11)$ had bilateral procedures. The duration of symptoms was between 14 and 86 months (mean 45 month). $81.8 \%$ of patients were male, and $18.2 \%$ were female.

All patients experienced aural fullness of different magnitudes. $72 \%$ had muffled hearing, 56\% had otalgia and $36 \%$ had tinnitus. All the patients had dull, retracted tympanic membrane on otoscopic finding. All patients showed mild to moderate conductive or mixed hearing loss (hearing threshold between 25 and $55 \mathrm{~dB}$ ). All patients had been previously treated with topical decongestant, nasal steroids and grommets. No bony carotid canal dehiscence was found by CT. RAST blood test showed evidence of aeroallergen allergy in $75 \%$ of subjects. The surgery was uneventful and all patients were discharge from hospital on the same day as surgery. Subjective postoperative improvement of symptoms (aural fullness) was perceived by 7 (63.6\%) patients at 1 week, $3(27.3 \%)$ patients at 2 months and 1 (9\%) patients at 6 months postoperatively. Aural fullness sensation completely disappeared in 10 (91\%) of cases at 6 months postoperatively. All the patients felt that the procedure was beneficial to them

Table 1- pre and post tymapanometry results

Table 2- pre and post EDQT-7 questionnaire data (subjective test)

\section{Discussion}

The diagnostic criteria for ETD have not been universally agreed. These may include subjective and/or objective criteria. Some patient with subjective symptoms suggestive of ETD have no objective abnormality. Many of the symptoms of ETD are also present in other conditions such as Meniere's Disease, TMJ dysfunction and Migraine ${ }^{2}$.

Balloon dilation Eustachian tuboplasty (BET) did not result in a statistically significant improvement in our objective outcome measure of tympanometry or pure tone audiometry. We did however, find evidence of subjective improvement in symptoms with the EDTQ-7, and all participants felt that the procedure was worth undergoing.

ETD may comprise of 2 separate pathological processes. One which responds to BET the other does not.

\section{References}

1. ED McCoul, VK Anand, PJ Christos. Validating the clinical assessment of eustachian tube dysfunction: The eustachian tube dysfunction questionnaire (ETDQ-7) Laryngoscope 2012;122: 1137-1141

2. Randrup Thomas Skov, Ovesen Therese,. Balloon Eustachian Tuboplasty: A Systematic Review Otolaryngology- Head and Neck Surgery 2015, vol 152(3),383-92
NHS 